Check for updates

Cite this: Mater. Adv., 2020, 1,54

Received 2nd March 2020 , Accepted 10th March 2020 DOI: $10.1039 / \mathrm{d} 0 \mathrm{ma} 00065 \mathrm{e}$ rsc.li/materials-advances

\title{
FeNiMo trimetallic nanoparticles encapsulated in carbon cages as efficient hydrogen evolution reaction electrocatalysts $\dagger$
}

\author{
Ziqi Zhang, ${ }^{a}$ Linchuan Cong, ${ }^{a}$ Zhuochen $Y u,{ }^{a}$ Lina Qu, ${ }^{a}$ Miaomiao Qian ${ }^{a}$ and \\ Weimin Huang (D)*ab
}

\begin{abstract}
Hydrogen is one of the most desirable alternatives to fossil fuels due to its renewability and large energy density. The electrocatalytic hydrogen evolution reaction (HER) is drawing more and more attention since it can produce $\mathrm{H}_{2}$ powered by renewable energy. Therefore, efficient and durable electrocatalysts are an urgent need. On the one hand, the high price and low reserve of noble metals hinder their further applications. On the other hand, various non-noble metal electrocatalysts cannot achieve satisfactory stability and efficiency. Thus, this paper reports a cheap and feasible way to synthesize a carbon cageencapsulated FeNiMo compound. It exhibits the desired overpotentials of $199 \mathrm{mV}$ at $10 \mathrm{~mA} \mathrm{~cm}^{-2}$ in an alkaline solution and $246 \mathrm{mV}$ at $10 \mathrm{~mA} \mathrm{~cm}{ }^{-2}$ in an acidic solution. Besides, it exhibits similar current density loss to commercial Pt/C after $10000 \mathrm{CV}$ cycles, which suggests satisfactory durability.
\end{abstract}

\section{Introduction}

The increasing greenhouse effect has aroused increasing attention towards renewable energy source conversion and storage. ${ }^{1}$ Hydrogen is considered as one of the most desirable alternatives to fossil fuels. ${ }^{2}$ The electrocatalytic hydrogen evolution reaction (HER) can produce $\mathrm{H}_{2}$ powered by renewable energy, including solar or wind energy. ${ }^{3,4}$ In order to drive HER with a lower overpotential, efficient and durable electrocatalysts are an urgent need. ${ }^{5}$ Although noble metals such as Pt, Ir and Ru are used as mainstream electrocatalysts, their high cost and low abundance hinder their further applications. ${ }^{6}$ Therefore, the use of low-cost and earth-abundant electrocatalysts to replace noble metal catalysts is necessary. ${ }^{7-9}$ Recently, many transition metals and their compounds have been used as non-noble electrocatalysts, including transition metal oxides, ${ }^{10}$ sulfides, ${ }^{11-14}$ phosphides, ${ }^{15-20}$ carbides, ${ }^{21}$ and nitrides. ${ }^{22}$ Among them, the compounds based on $\mathrm{Co}, \mathrm{Fe}$ and $\mathrm{Ni}$ are most frequently used as electrocatalysts for HER due to their low cost and deficient $3 \mathrm{~d}$ electron structures. ${ }^{23-25}$ However, due to their weak electronic conductivity and stability, the electrocatalysts based on $\mathrm{Fe}, \mathrm{Ni}$ and Co are still not able to compete with noble-metal-based

\footnotetext{
${ }^{a}$ College of Chemistry, Jilin University, Changchun 130012, China. E-mail: huangwm@jlu.edu.cn; Tel: +86-431-80561579

${ }^{b}$ Key Laboratory of Physics and Technology for Advanced Batteries of Ministry of Education, Jilin University, Changchun 130012, China

$\dagger$ Electronic supplementary information (ESI) available. See DOI: 10.1039/ d0ma00065e
}

electrocatalysts. ${ }^{26}$ Therefore, we aim to solve these issues in two ways. First, we can establish unique carbon nanostructures, such as carbon nanotubes ${ }^{27}$ and graphene, ${ }^{28}$ to enhance the conductivity and stability morphologically. Second, we can combine the metals (Mo) on the left half of the transition metals in the periodic table with the metals ( $\mathrm{Fe}$ and $\mathrm{Ni}$ ) on the right half of the series with more filled d-bands, which can build well-pronounced synergism in electrocatalysis. ${ }^{29}$

In this paper, we report a new $\mathrm{Fe}, \mathrm{Ni}$ and Mo trimetallic compound encapsulated in a carbon cage as an efficient HER electrocatalyst. This material was synthesized by a two-step hydrothermal reaction at room temperature and one-step direct carbonization, which is facile, low-cost and environmentally friendly. It exhibits the desired overpotentials of $199 \mathrm{mV}$ at $10 \mathrm{~mA} \mathrm{~cm}^{-2}$ in an alkaline solution and $246 \mathrm{mV}$ at $10 \mathrm{~mA} \mathrm{~cm}^{-2}$ in an acidic solution. Besides, it has satisfactory durability, which is better than that of a commercial $\mathrm{Pt} / \mathrm{C}$ catalyst.

\section{Experimental section}

\subsection{Reagents}

Potassium ferricyanide $\left(\mathrm{K}_{3}\left[\mathrm{Fe}(\mathrm{CN})_{6}\right]\right.$, analytical reagent), potassium ferrocyanide trihydrate $\left(\mathrm{K}_{4}\left[\mathrm{Fe}(\mathrm{CN})_{6}\right] \cdot 3 \mathrm{H}_{2} \mathrm{O}\right.$, analytical reagent), sodium citrate $\left(\mathrm{Na}_{3} \mathrm{C}_{6} \mathrm{H}_{5} \mathrm{O}_{7}, 99 \%\right)$, ethyl alcohol $\left(\mathrm{C}_{2} \mathrm{H}_{5} \mathrm{OH}, \geq 99.8 \%\right)$, sulfuric acid $\left(\mathrm{H}_{2} \mathrm{SO}_{4}, 98 \%\right)$ and potassium hydroxide (KOH, 96\%) were obtained from Beijing Chemical Works. Nickel nitrate hexahydrate $\left(\mathrm{Ni}\left(\mathrm{NO}_{3}\right)_{2} \cdot 6 \mathrm{H}_{2} \mathrm{O}, 98 \%\right)$ and ammonium molybdate tetrahydrate $\left(\mathrm{H}_{24} \mathrm{Mo}_{7} \mathrm{~N}_{6} \mathrm{O}_{24} \cdot 4 \mathrm{H}_{2} \mathrm{O}\right)$ were 
obtained from Aladdin. Pt/C (20 wt\%, JM), Nafion (5.0 wt\%, Dupont), and $\mathrm{N}_{2}$ gas (99.99\%) were also employed. All chemical reagents were used as received without further purification. All aqueous solutions were prepared with ultrapure water (resistivity of $18.25 \mathrm{M} \Omega \mathrm{cm}$ ).

\subsection{Physical characterization}

Scanning electron microscopy (SEM) was performed on a HITACHI SU020 microscope. Transmission electron microscopy (TEM) and elemental mapping were performed on an FEI Tecnai G20/JEM2010 microscope. X-ray photoelectron spectra (XPS) were recorded on a Thermo ESCALAB 250Xi with an excitation source of $\mathrm{Al} \mathrm{K} \alpha$ radiation. X-ray diffraction (XRD) patterns were carried out using an Empyrean (PANalytical B.V.) with a $\mathrm{Cu} K \alpha$ radiation source $\left(\lambda_{1}=1.5406 \AA\right)$ operating at $40.0 \mathrm{kV}$ and $40.0 \mathrm{~mA}$, and the diffraction data were recorded in the $2 \theta$ range of $5-80^{\circ}$ with a scan rate of 4 degrees per min.

\subsection{Preparation of $\mathrm{Fe}^{3+} \mathrm{NiMoC}$}

In a typical procedure, ${ }^{30} 0.6 \mathrm{mmol}$ of nickel nitrate and $0.9 \mathrm{mmol}$ of sodium citrate were dissolved in $20 \mathrm{~mL}$ of deionized (DI) water to form solution $\mathrm{A}$, and $0.4 \mathrm{mmol}$ of potassium ferricyanide was dissolved in another $20 \mathrm{~mL}$ of DI water to form solution B. Solutions A and B were then mixed under stirring for $1 \mathrm{~min}$. The obtained mixed solution was aged for $18 \mathrm{~h}$ at room temperature. The mixed solution was centrifuged and washed several times with DI water and dried in a vacuum overnight at $60{ }^{\circ} \mathrm{C}$ to obtain the $\mathrm{Fe}-\mathrm{Ni}$ Prussian blue analogue ( $\left.\mathrm{Fe}^{3+} \mathrm{Ni}-\mathrm{PBA}\right)$. In addition, $0.4 \mathrm{mmol}$ of ferrocyanide trihydrate was used to take the place of $0.4 \mathrm{mmol}$ of potassium ferricyanide and the product was named $\mathrm{Fe}^{2+} \mathrm{Ni}-\mathrm{PBA}$.

Next, $200 \mathrm{mg}$ of $\mathrm{Fe}^{3+} \mathrm{Ni}$-PBA was dissolved in $10 \mathrm{ml}$ of $\mathrm{DI}$ water, which was subsequently injected into $10 \mathrm{ml}$ of DI water containing $200 \mathrm{mg}$ of ammonium molybdate tetrahydrate. The mixed solution was then stirred for $24 \mathrm{~h}$ at room temperature, centrifuged with DI water several times and dried overnight in a vacuum at $60{ }^{\circ} \mathrm{C}$ to get $\mathrm{Fe}, \mathrm{Ni}$ and Mo compounds named $\mathrm{Fe}^{3+}$ NiMo. In addition, $\mathrm{Fe}^{2+} \mathrm{Ni}-\mathrm{PBA}$ was treated in the same way to get $\mathrm{Fe}^{2+} \mathrm{NiMo}$. The precipitate $\left(\mathrm{Fe}^{2+} \mathrm{NiMo}\right.$ or $\left.\mathrm{Fe}^{3+} \mathrm{NiMo}\right)$ was heated at $800{ }^{\circ} \mathrm{C}$ for $4 \mathrm{~h}$ at a rate of $3{ }^{\circ} \mathrm{C} \mathrm{min}{ }^{-1}$ in a tube furnace and in $\mathrm{N}_{2}$ atmosphere to obtain the carbide of FeNiMo compounds. The final products were named $\mathrm{Fe}^{3+} \mathrm{NiMoC}$ or $\mathrm{Fe}^{2+}$ NiMoC, respectively. As control groups, $\mathrm{Fe}^{2+} \mathrm{Ni}-\mathrm{PBA}$ and $\mathrm{Fe}^{3+} \mathrm{Ni}$-PBA were heated under the same conditions as above to get the corresponding carbonization products, which were named $\mathrm{Fe}^{2+} \mathrm{Ni}-\mathrm{PBAC}$ and $\mathrm{Fe}^{3+} \mathrm{Ni}-\mathrm{PBAC}$, respectively.

\subsection{Cathode preparation}

Briefly, $5 \mathrm{mg}$ of $\left(\mathrm{Fe}^{2+} \mathrm{Ni}-\mathrm{PBAC}, \mathrm{Fe}^{3+} \mathrm{Ni}-\mathrm{PBAC}, \mathrm{Fe}^{2+} \mathrm{NiMoC}\right.$, $\mathrm{Fe}^{3+}$ NiMoC or $\mathrm{Pt} / \mathrm{C}(20 \mathrm{wt} \%)$ ) was dispersed in $240 \mu \mathrm{L}$ of a mixed solution of ethyl alcohol, $240 \mu \mathrm{L}$ of ultrapure water and $20 \mu \mathrm{L}$ of $5 \mathrm{wt} \%$ Nafion and ultrasonicated for $10 \mathrm{~min}$. Next, $5 \mu \mathrm{L}$ of liquid was pipetted onto the surface of a glassy carbon electrode (GCE, $3 \mathrm{~mm}$ ) (loading $\sim 0.7077 \mathrm{mg} \mathrm{cm}^{-2}$ ) and allowed to dry naturally. The modified GCE served as the working electrode.

\subsection{Electrochemical measurements}

Electrochemical measurements were performed using a CHI 660E electrochemical workstation with a three-electrode system that included a working electrode (GCE), a counter electrode (Pt foil, $\left.1 \times 1 \mathrm{~cm}^{2}\right)$ and a reference electrode $(\mathrm{Hg} / \mathrm{HgO}$, $1 \mathrm{M} \mathrm{KOH}$ electrolyte) in $1 \mathrm{M} \mathrm{KOH}$ solution, or a $\mathrm{Hg} / \mathrm{Hg}_{2} \mathrm{SO}_{4}$ (saturated $\mathrm{K}_{2} \mathrm{SO}_{4}$ electrolyte) electrode in $0.5 \mathrm{M} \mathrm{H}_{2} \mathrm{SO}_{4}$ solution. The experimental potential values were calibrated by using the following equation: $E$ vs. $\mathrm{RHE}=E v$ s. $\mathrm{Hg} / \mathrm{HgO}+0.098+0.059 \mathrm{pH}$; $E$ vs. $\mathrm{RHE}=E$ vs. $\mathrm{Hg} / \mathrm{Hg}_{2} \mathrm{SO}_{4}+0.616+0.059 \mathrm{pH}$. Before the test, $\mathrm{N}_{2}$ flow $\left(20 \mathrm{~mL} \mathrm{~min}^{-1}\right.$ ) was continuously fed to the cathode through the electrolyte in the cell for $30 \mathrm{~min}$. The linear sweep voltammetry (LSV) experiments were performed at a scan rate of $10 \mathrm{mV} \mathrm{s}^{-1}$ from 0.2 to $-0.7 \mathrm{~V}$ (vs. RHE) in $\mathrm{N}_{2}$-saturated $0.5 \mathrm{M} \mathrm{H}_{2} \mathrm{SO}_{4}$ or $1 \mathrm{M}$ $\mathrm{KOH}$ solution, respectively. Electrochemical impedance spectra (EIS) measurements were performed at an overpotential of $300 \mathrm{mV}$ (vs. RHE) with frequencies from 0.1 to $100000 \mathrm{~Hz}$ and an amplitude of $5 \mathrm{mV}$. The electrochemically active surface area (ECSA) was estimated by CVs and was tested from -0.80 to $-0.70 \mathrm{~V}\left(v s . \mathrm{Hg} / \mathrm{HgO}\right.$ ) with a scan rate from 10 to $100 \mathrm{mV} \mathrm{s}^{-1}$ in $\mathrm{N}_{2}$-saturated $1 \mathrm{M} \mathrm{KOH}$, or tested from -0.65 to $-0.55 \mathrm{~V}$ (vs. $\mathrm{Hg} / \mathrm{Hg}_{2} \mathrm{SO}_{4}$ ) with a scan rate from 10 to $100 \mathrm{mV} \mathrm{s}^{-1}$ in $\mathrm{N}_{2}$-saturated $0.5 \mathrm{M} \mathrm{H}_{2} \mathrm{SO}_{4}$. Durability cyclic voltammetry (CV) tests were conducted from -0.4 to $0 \mathrm{~V}$ (vs. RHE) in $\mathrm{N}_{2}$-saturated $0.5 \mathrm{M} \mathrm{H}_{2} \mathrm{SO}_{4}$ or $1 \mathrm{M} \mathrm{KOH}$ solution with the scan rate of $100 \mathrm{mV} \mathrm{s}^{-1}$ for 10000 segments and the differences in the LSV curves before and after CVs were compared.

\section{Results and discussion}

\subsection{Physical characterization}

SEM was used to observe the morphologies of the samples before carbonization. As shown in Fig. $1 \mathrm{a}$ and $\mathrm{b}$, the $\mathrm{Fe}^{2+} \mathrm{Ni}-\mathrm{PBA}$ has irregular aggregation while the $\mathrm{Fe}^{3+} \mathrm{Ni}-\mathrm{PBA}$ is made of independent cubic nanocrystals. The addition of ammonium molybdate tetrahydrate made the $\mathrm{Fe}^{2+} \mathrm{Ni}$-PBA particles stick together (Fig. 1c) while most of the $\mathrm{Fe}^{3+} \mathrm{Ni}$-PBA cubes remained

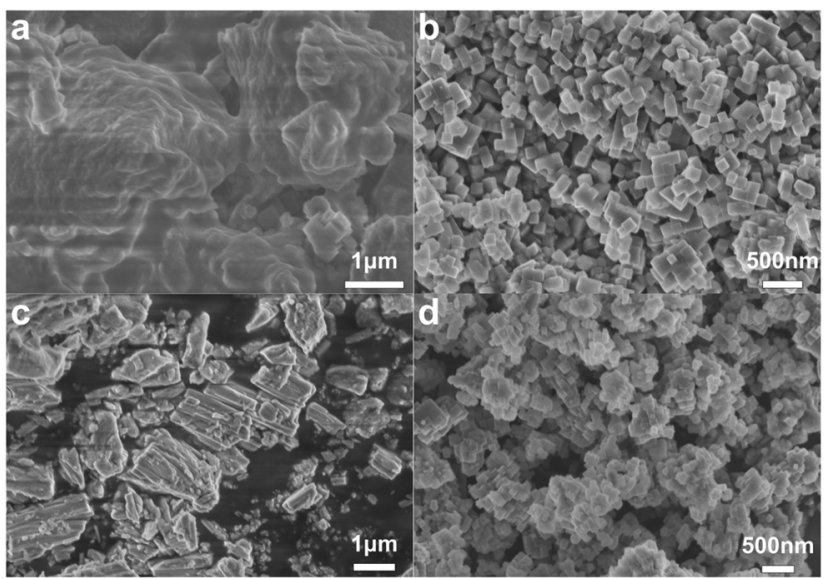

Fig. 1 SEM images of $\mathrm{Fe}^{2+} \mathrm{Ni}-\mathrm{PBA}(\mathrm{a}), \mathrm{Fe}^{3+} \mathrm{Ni}-\mathrm{PBA}(\mathrm{b}), \mathrm{Fe}^{2+} \mathrm{NiMo}(\mathrm{c})$, and $\mathrm{Fe}^{3+} \mathrm{NiMo}(\mathrm{d})$ before carbonization. 


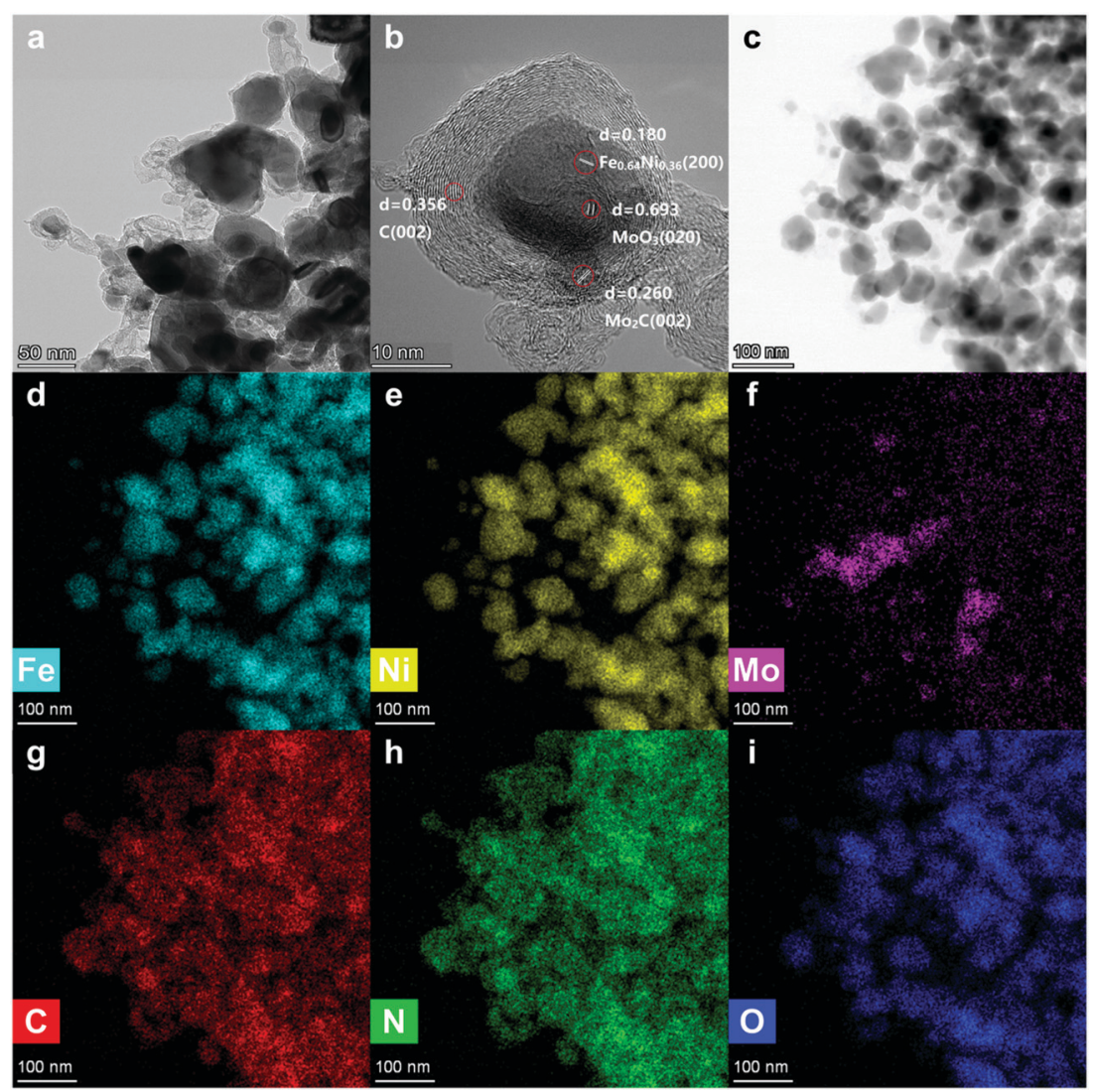

Fig. 2 TEM images $(a-c)$ and the corresponding mapping images $(d-i)$ of $\mathrm{Fe}^{3+} \mathrm{NiMoC}$

uniform and independent after mixing (Fig. 1d), which allowed them to form dispersive nanoparticles after carbonization (Fig. 2a), thus enlarging the surface area and increasing the number of active sites.

In Fig. 2a, the metallic nanoparticles are surrounded by graphitic layers that can serve as a "cage", encapsulating the metallic compounds inside. These carbon cages are connected by carbonized tubes made from $\mathrm{N}$-doped carbon (Fig. $2 \mathrm{~g}$ and $\mathrm{h}$ ).

In order to investigate the morphology of the single carbon cage, high-resolution TEM was carried out. In Fig. $2 \mathrm{~b}$, the Fe, $\mathrm{Ni}$ and Mo compounds, including $\mathrm{Fe}_{0.64} \mathrm{Ni}_{0.36}, \mathrm{Mo}_{2} \mathrm{C}$ and $\mathrm{MoO}_{3}$, are wrapped by the graphitic layers. The graphitic layers can serve as a carbon cage and encapsulate the $\mathrm{Fe}, \mathrm{Ni}$ and $\mathrm{Mo}$ compounds inside, which can protect the active sites from the environment. The graphitic layers can also serve as a desirable electron transport medium due to its excellent conductivity. Thus, the graphitic layer structure can enhance the durability and improve the catalytic efficiency at the same time. Besides, the graphitic layers were not oriented parallel to the axis and showed considerable defects and edges on the surface, ${ }^{31}$ which can improve the surface affinity for $\mathrm{H}^{+}$in the solution.

The XRD pattern of $\mathrm{Fe}^{3+}$ NiMoC is shown in Fig. 3a. The typical peak at $\approx 25^{\circ}$ indicates the (002) face of graphite carbon, which is characteristic of the carbon framework. The diffraction peaks at $43.6^{\circ}, 50.8^{\circ}$, and $74.7^{\circ}$ can be indexed to the (111), (200), and (220) planes of $\mathrm{Fe}_{0.64} \mathrm{Ni}_{0.36}$, and the peaks at $34.3^{\circ}$, $37.9^{\circ}, 39.3^{\circ}, 52.1^{\circ}, 61.4^{\circ}, 69.5^{\circ}, 72.3^{\circ}, 74.5^{\circ}$ and $75.5^{\circ}$ can be assigned to the (021), (200), (121), (221), (040), (321), (042), (240) and (142) planes of $\mathrm{Mo}_{2} \mathrm{C}$. ${ }^{32}$

In order to investigate the compound surface including the chemical composition and element bonding configurations, X-ray photoelectron spectroscopy (XPS) was carried out for $\mathrm{Fe}^{3+} \mathrm{NiMoC}$. As shown in Fig. 3b, the existence of C, N, O, Fe, $\mathrm{Ni}$ and Mo with the atomic contents of C-43.15\%, N-22.47\%, O-20.15\%, Fe-3.75\%, N-2.16\% and Mo-8.32\% was confirmed. In the C 1s spectra (Fig. 3c), the peaks were observed at 284.5, 285.5 , and $286.5 \mathrm{eV}$, which can be ascribed to $\mathrm{C}=\mathrm{C}, \mathrm{C}-\mathrm{C}$ and $\mathrm{C}-\mathrm{O}$, respectively. ${ }^{3,34}$ Fig. $3 \mathrm{~d}$ shows the high-resolution spectrum of $\mathrm{N} 1 \mathrm{~s}$, which presents 4 types of $\mathrm{N}$ coordination environments at $398.6 \mathrm{eV}$ for pyridinic- $\mathrm{N}, 400.3 \mathrm{eV}$ for pyrrolic-N, $401.1 \mathrm{eV}$ for graphitic-N and $402.7 \mathrm{eV}$ for oxidized-N. ${ }^{35,36}$ Meanwhile, the $\mathrm{N}$ content was determined to be 3.94 at\%, which suggests that $\mathrm{N}$ atoms have been successfully doped into the carbon network. $\mathrm{N}$ doping in the porous carbon is beneficial for stabilizing metallic $\mathrm{Fe}$, Ni and Mo as well as their compounds. In the meantime, it can regulate the electronic structure and surface permeability of catalyst. ${ }^{5}$ The $\mathrm{O} 1 \mathrm{~s}$ spectrum in Fig. 3e contains three peaks at $530.4 \mathrm{eV}, 531.0 \mathrm{eV}$ and $532.1 \mathrm{eV}$ belonging to lattice oxygen, $-\mathrm{OH}$ groups and adsorbed $\mathrm{H}_{2} \mathrm{O}$, respectively. These three peaks all shifted to high binding energies compared to pure $\mathrm{MoO}_{3},{ }^{37}$ suggesting that electrons were transferred from the oxygen of $\mathrm{MoO}_{3}$ to $\mathrm{Ni}$, which decreased the electron cloud density of oxygen. Therefore, the binding energies changed and partial oxygen vacancies were 

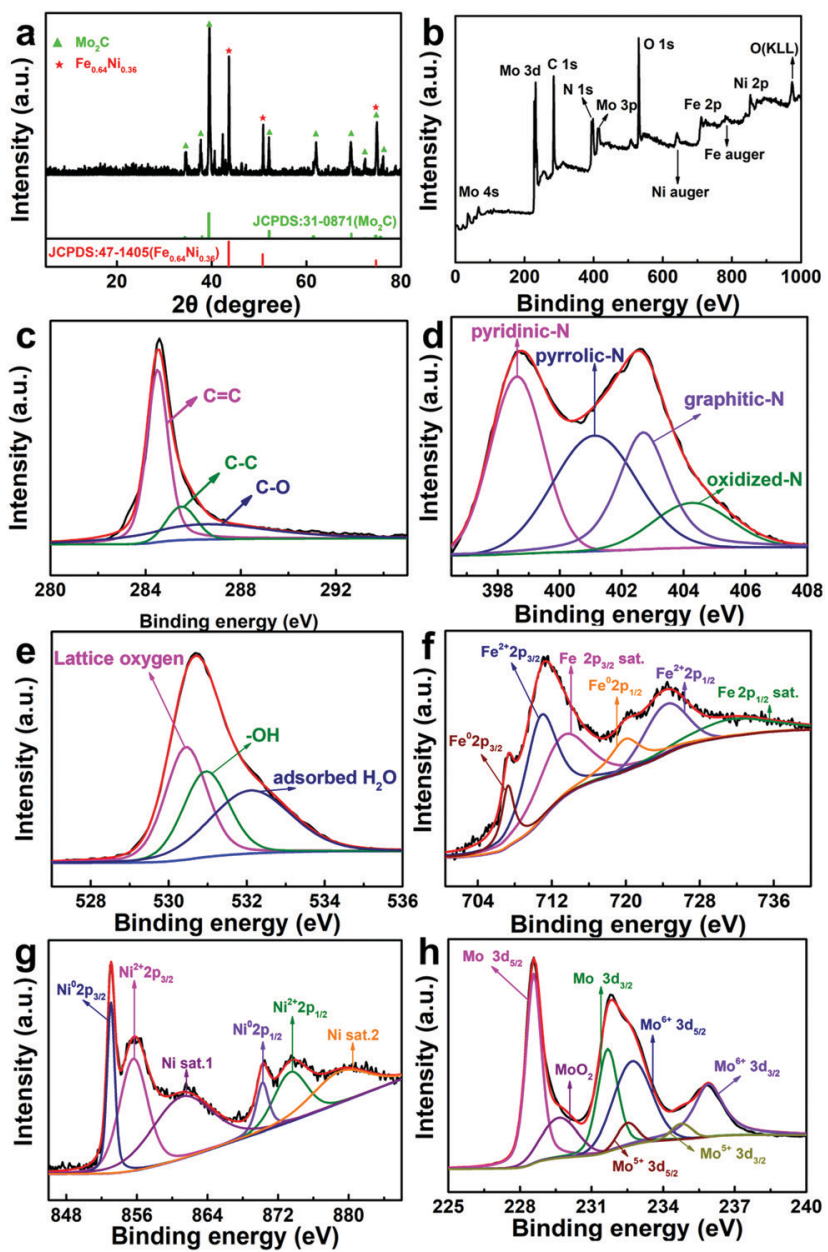

Fig. 3 XRD pattern (a), XPS survey spectrum (b) and the corresponding high-resolution spectra $(c-h)$ of $\mathrm{Fe}^{3+} \mathrm{NiMoC}$.

formed. ${ }^{38,39}$ In Fig. $3 \mathrm{f}$ and $\mathrm{g}$, the $\mathrm{Fe}^{0} 2 \mathrm{p}$ and $\mathrm{Ni}^{0} 2 \mathrm{p}$ peaks can be ascribed to the $\mathrm{Fe}^{3+}$ and $\mathrm{Ni}^{2+}$ ions being reduced to $\mathrm{Fe}_{0.64} \mathrm{Ni}_{0.36}$ at high temperature. The $\mathrm{Fe}^{2+} 2 \mathrm{p}$ and $\mathrm{Ni}^{2+} 2 \mathrm{p}$ peaks may belong to the coordination center of N-doped carbon. In addition, the Fe and $\mathrm{Ni}$ satellite peaks can be ascribed to the formation of the iron carbide and the spinel structure $\mathrm{NiFe}_{2} \mathrm{O}_{4},{ }^{40,41}$ which were possibly produced by calcining the $\mathrm{Fe}^{3+}, \mathrm{Ni}^{2+}$ and sodium citrate at high temperatures and both have been reported to be excellent active centres toward the HER. ${ }^{31}$ In Fig. $3 \mathrm{~h}$, the Mo $3 \mathrm{~d}$ peaks at $232.7 \mathrm{eV}$ and $235.8 \mathrm{eV}$ are assigned to $\mathrm{Mo}^{6+} 3 \mathrm{~d}_{5 / 2}$ and $\mathrm{Mo}^{6+} 3 \mathrm{~d}_{3 / 2}$ of $\mathrm{MoO}_{3}$ produced by the thermal decomposition of ammonium molybdate. ${ }^{42} \mathrm{Mo}^{5+}$ peaks $(232.5 \mathrm{eV}$ and $234.8 \mathrm{eV})$ reveal the formation of oxygen vacancies due to the substitution of $\mathrm{Ni}$ and $\mathrm{Fe}$ atoms for Mo atoms in $\mathrm{MoO}_{3}$ lattice. ${ }^{43}$

In the XRD patterns, $\mathrm{Mo}_{2} \mathrm{C}$ has the highest content among the Mo compounds while XPS indicates that the oxide of Mo dominates. This is mostly because XRD studies the bulk phase while XPS focuses on the surface; i.e., $\mathrm{Fe}^{3+} \mathrm{NiMoC}$ is mainly made up of $\mathrm{Fe}_{064} \mathrm{Ni}_{036}$ and $\mathrm{Mo}_{2} \mathrm{C}$ with the surface oxidation of Mo. In general, the $\mathrm{N}$-doped carbon network established by carbonizing $\mathrm{Fe}^{3+} \mathrm{Ni}-\mathrm{PBA}$ can serve as a conductive fundamental base to tightly immobilize carbon cages. The carbon cages can form a natural barrier to keep metallic active sites inside from being damaged by the environment. The low oxygen coordinated defect sites in the $\mathrm{Fe}, \mathrm{Ni}$ and Mo compounds can serve as the HER active center, thus enhancing the electrocatalytic activity..$^{30,44,45}$

\subsection{HER catalytic activities in acidic solution}

The HER catalytic performance was firstly tested in $0.5 \mathrm{M}$ $\mathrm{H}_{2} \mathrm{SO}_{4}$. As seen in Fig. $4 \mathrm{a}$ and $\mathrm{b}, \mathrm{Fe}^{3+} \mathrm{Ni}$-PBAC (471 $\mathrm{mV} v s$. RHE) and $\mathrm{Fe}^{3+}$ NiMoC (246 mV vs. RHE) showed lower overpotentials as compared to $\mathrm{Fe}^{2+} \mathrm{Ni}$-PBAC $(616 \mathrm{mV}$ vs. RHE) and $\mathrm{Fe}^{2+} \mathrm{NiMoC}\left(393 \mathrm{mV}\right.$ vs. RHE) at $10 \mathrm{~mA} \mathrm{~cm}{ }^{-2}$, respectively, which suggests that the electrocatalysts synthesized by $\mathrm{Fe}^{3+}$ have better catalytic activity toward the HER. This is probably due to the uniform and independent catalytic units providing a larger surface area and more active sites. On the other hand, $\mathrm{Fe}^{2+} \mathrm{NiMoC}$ and $\mathrm{Fe}^{3+} \mathrm{NiMoC}$ showed lower overpotentials (393 mV and $246 \mathrm{mV} v$ s. RHE) compared to the $\mathrm{Fe}^{2+} \mathrm{Ni}$-PBAC and $\mathrm{Fe}^{3+} \mathrm{Ni}$-PBAC (616 $\mathrm{mV}$ and $417 \mathrm{mV}$ vs. RHE) at $10 \mathrm{~mA} \mathrm{~cm}{ }^{-2}$, respectively, which indicates that the addition of Mo and its compounds can enhance the catalytic efficiency toward the HER. This is consistent with the results of a previous report. ${ }^{46}$ For comparison, the $20 \% \mathrm{Pt} / \mathrm{C}$ was tested in the same way and showed an overpotential of $42 \mathrm{mV}$ (vs. RHE) (Fig. 3a).

To gain insight into the kinetics and mechanism for the HER, the Tafel plots derived from the corresponding polarization curves are presented in Fig. 4c. The $\mathrm{Fe}^{3+} \mathrm{NiMoC}$ displays

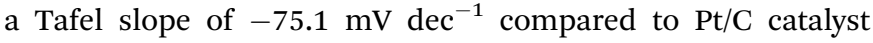
$\left(-33.0 \mathrm{mV} \mathrm{dec}{ }^{-1}\right)$. The Tafel slope is an intrinsic property of the electrocatalytic HER activity, which is related to the ratedetermining step of the HER. A lower Tafel slope shows better HER kinetics. ${ }^{47}$ In the aqueous electrolyte, $\mathrm{H}^{+}$ions obtained electrons to form $\mathrm{H}$ atoms and were adsorbed on the surface of the working electrode (Volmer reaction, $\mathrm{H}_{3} \mathrm{O}^{+}+\mathrm{e}^{-} \rightarrow \mathrm{H}_{\text {ads }}$ ), ${ }^{48}$ followed by either an electrochemical desorption step (Heyrovsky reaction, $\mathrm{H}_{\text {ads }}+\mathrm{H}_{3} \mathrm{O}^{+}+\mathrm{e}^{-} \rightarrow \mathrm{H}_{2}$ ) or a chemical
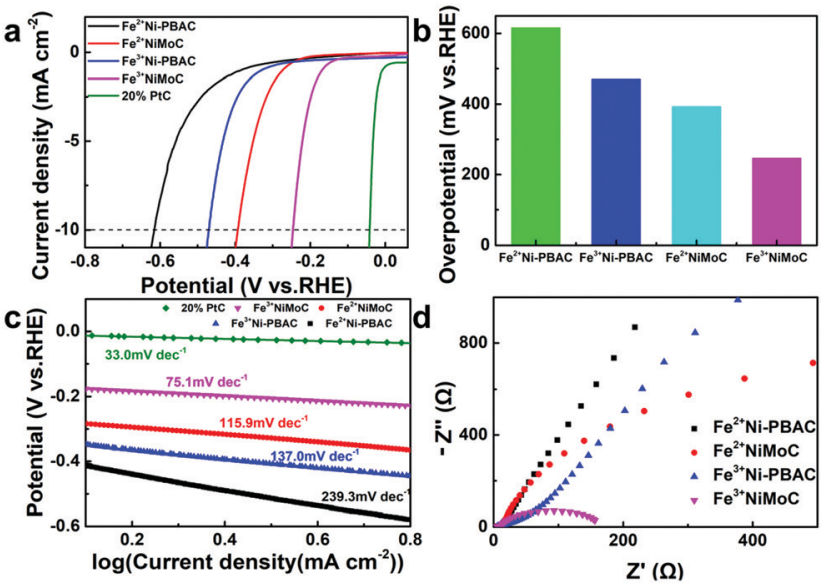

Fig. 4 (a) iR-corrected LSV curves of $\mathrm{Fe}^{2+} \mathrm{Ni}-\mathrm{PBAC}, \mathrm{Fe}^{3+} \mathrm{Ni}-\mathrm{PBAC}$, $\mathrm{Fe}^{2+} \mathrm{NiMoC}, \mathrm{Fe}^{3+} \mathrm{NiMoC}$ and $20 \% \mathrm{Pt} / \mathrm{C}$; (b) the corresponding overpotentials at $10 \mathrm{~mA} \mathrm{~cm}^{-2}$. (c) Tafel plots and (d) EIS spectra for the HER at $-0.3 \mathrm{~V}$ (vs. RHE). The electrolyte solution was $0.5 \mathrm{M} \mathrm{H}_{2} \mathrm{SO}_{4}$ 
desorption step $\left(\mathrm{H}_{\mathrm{ads}}+\mathrm{H}_{\mathrm{ads}} \rightarrow \mathrm{H}_{2}\right)$ to form hydrogen molecules. ${ }^{5}$ The theoretical Tafel slopes of the Volmer, Heyrovsky and Tafel reactions are $-120,-40$ and $-30 \mathrm{mV} \mathrm{dec}^{-1}$, respectively. The Tafel slope of the $\mathrm{Fe}^{3+} \mathrm{NiMoC}$ was $-75.1 \mathrm{mV}$ $\operatorname{dec}^{-1}$, which is a Volmer-Heyrovsky mechanism with the Heyrovsky step is the rate-determining step. ${ }^{48}$ In order to study the charge transfer resistances of these 4 samples, the electrochemical impedance spectra were employed. Fig. $4 \mathrm{~d}$ is the EIS of $\mathrm{Fe}^{2+} \mathrm{Ni}-\mathrm{PBAC}, \mathrm{Fe}^{3+} \mathrm{Ni}-\mathrm{PBAC}, \mathrm{Fe}^{2+} \mathrm{NiMoC}$ and $\mathrm{Fe}^{3+} \mathrm{NiMoC}$ at $-0.3 \mathrm{~V}$ (vs. RHE). The $\mathrm{Fe}^{3+} \mathrm{NiMoC}$ has the minimum charge transfer resistance and thus promotes the kinetics of the HER. Besides, the charge transfer resistances and Tafel slopes, $\mathrm{Fe}^{3+}$ NiMoC $<\mathrm{Fe}^{2+}$ NiMoC $<\mathrm{Fe}^{3+}$ Ni-PBAC $<\mathrm{Fe}^{2+}$ Ni-PBAC which is consistent with the trend of the HER overpotentials mentioned above (Fig. $4 \mathrm{a}$ and $\mathrm{b}$ ).

\subsection{HER catalytic activities in alkaline solution}

The HER catalytic performance was also tested in $1 \mathrm{M} \mathrm{KOH}$. As shown in Fig. 5b and c, $\mathrm{Fe}^{3+}$ NiMoC exhibits the smallest Tafel

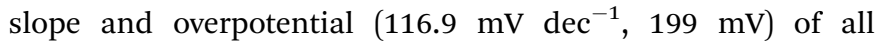
samples $\left(\mathrm{Fe}^{3+} \mathrm{Ni}-\mathrm{PBAC}\left(133.1 \mathrm{mV} \mathrm{dec}{ }^{-1}, 298 \mathrm{mV}\right), \mathrm{Fe}^{2+} \mathrm{Ni}^{-}\right.$ $\operatorname{MoC}\left(135.2 \mathrm{mV} \mathrm{dec}{ }^{-1}, 355 \mathrm{mV}\right), \mathrm{Fe}^{2+} \mathrm{Ni}-\mathrm{PBAC}\left(209.7 \mathrm{mV} \mathrm{dec}^{-1}\right.$, $548 \mathrm{mV})$ ) except for the commercial Pt/C catalyst (54.2 $\mathrm{mV} \mathrm{dec}^{-1}$, $43 \mathrm{mV}$ ), which suggests that the HER kinetics of $\mathrm{Fe}^{3+} \mathrm{NiMoC}$ is favorable and the current density of $\mathrm{Fe}^{3+} \mathrm{NiMoC}$ will increase faster as the potential becomes more negative. EIS spectra are also shown in Fig. 5d, illustrating that $\mathrm{Fe}^{3+} \mathrm{NiMoC}$ has the smallest intrinsic resistance and charge transfer resistance, which facilitates the kinetics towards the HER, too.

It is worth noting that in alkaline solution $(1 \mathrm{M} \mathrm{KOH})$, the order of catalytic efficiency is as follows: $\mathrm{Fe}^{3+} \mathrm{NiMoC}>$ $\mathrm{Fe}^{3+} \mathrm{Ni}$-PBAC $>\mathrm{Fe}^{2+} \mathrm{NiMoC}>\mathrm{Fe}^{2+} \mathrm{Ni}$-PBAC. However, in acidic solution $\left(0.5 \mathrm{M} \mathrm{H}_{2} \mathrm{SO}_{4}\right)$, the order is $\mathrm{Fe}^{3+} \mathrm{NiMoC}>$ $\mathrm{Fe}^{2+} \mathrm{NiMoC}>\mathrm{Fe}^{3+} \mathrm{Ni}$-PBAC $>\mathrm{Fe}^{2+} \mathrm{Ni}$-PBAC. In other words, the $\mathrm{Fe}^{3+} \mathrm{Ni}$-PBAC shows a better catalytic effect in alkaline solution while the $\mathrm{Fe}^{2+} \mathrm{NiMoC}$ is better in the acidic solution.
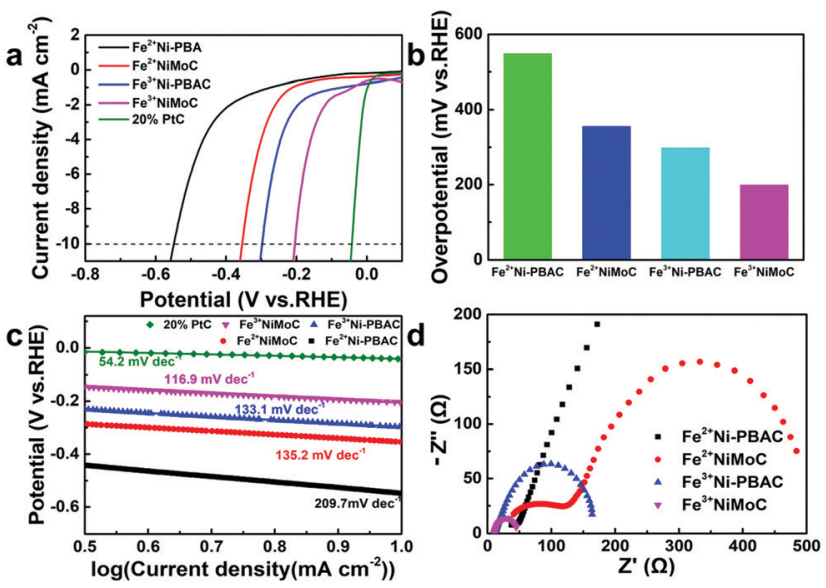

Fig. 5 iR-corrected LSV curves of $\mathrm{Fe}^{2+} \mathrm{Ni}-\mathrm{PBAC}, \mathrm{Fe}^{3+} \mathrm{Ni}-\mathrm{PBAC}, \mathrm{Fe}^{2+} \mathrm{NiMoC}$ $\mathrm{Fe}^{3+} \mathrm{NiMoC}$ and $20 \% \mathrm{Pt} / \mathrm{C}$ (a); the corresponding overpotentials at $10 \mathrm{~mA} \mathrm{~cm}^{-2}$ (b); Tafel plots (c) and EIS spectra for HER at $-0.3 \mathrm{~V}$ (vs. RHE) (d). The electrolyte solution was $1 \mathrm{M} \mathrm{KOH}$.
This is probably because in acidic solution, the desorption of $\mathrm{H}_{2}\left(\mathrm{H}_{\mathrm{ads}}+\mathrm{H}_{\mathrm{ads}} \rightarrow \mathrm{H}_{2}\right)$ is the rate-determining step due to the abundant $\mathrm{H}^{+}$environment, and the $\mathrm{Fe}^{2+} \mathrm{NiMoC}$ has a weaker adsorption capacity toward $\mathrm{H}_{\text {ads }}$ so it exhibits a better catalytic effect than $\mathrm{Fe}^{3+} \mathrm{Ni}$-PBAC. When it comes to the alkaline solution, the adsorption of $\mathrm{H}^{+}\left(\mathrm{H}_{3} \mathrm{O}^{+}+\mathrm{e}^{-} \rightarrow \mathrm{H}_{\text {ads }}\right)$ is the ratedetermining step on account of the lack of $\mathrm{H}^{+}$. Therefore, the independent catalytic units and larger surface area led to $\mathrm{Fe}^{3+}$ Ni-PBAC demonstrating preferable catalytic performance in alkaline solution.

\subsection{Durability and activities of electrocatalyst}

The ECSA was estimated by CVs with the equation ECSA = $C_{\mathrm{dl}} / C_{\mathrm{s}}$ (where $C_{\mathrm{dl}}$ is the double layer capacitance, $C_{\mathrm{s}}$ is the capacitive behavior). The larger ECSA means more active sites. ${ }^{49}$ Since the $C_{\mathrm{s}}$ of $\mathrm{Fe}^{3+} \mathrm{NiMoC}$ is unknown, we can estimate the ECSA by comparing the value of $C_{\mathrm{dl}} ; C_{\mathrm{dl}}$ can be calculated from the slope of the $\Delta J$-scan rate line. ${ }^{50}$ The $\mathrm{CV}$ was firstly tested from -0.65 to $-0.55 \mathrm{~V}\left(v s\right.$. $\mathrm{Hg} / \mathrm{Hg}_{2} \mathrm{SO}_{4}$ ) with scan rates from 10 to $100 \mathrm{mV} \mathrm{s}^{-1}$ in $0.5 \mathrm{M} \mathrm{H}_{2} \mathrm{SO}_{4}$ (Fig. 6a and b). $C_{\mathrm{dl}}$ was calculated with $\Delta J-0.60 \mathrm{~V}$ ( $\left.v s . \mathrm{Hg} / \mathrm{Hg}_{2} \mathrm{SO}_{4}\right)$. The value of $C_{\mathrm{dl}}\left(\mu \mathrm{F} \mathrm{cm}{ }^{-2}\right)$ is half of the slope,$^{51}$ which is $12.9 \mu \mathrm{F} \mathrm{cm} ~^{-2}$ for $\mathrm{Fe}^{3+} \mathrm{NiMoC}$, $2.9 \mu \mathrm{F} \mathrm{cm}^{-2}$ for $\mathrm{Fe}^{3+} \mathrm{Ni}$-PBAC, $1.6 \mu \mathrm{F} \mathrm{cm}{ }^{-2}$ for $\mathrm{Fe}^{2+} \mathrm{NiMoC}$ and $0.5 \mu \mathrm{F} \mathrm{cm}{ }^{-2}$ for $\mathrm{Fe}^{2+} \mathrm{Ni}$-PBAC. The $\mathrm{CV}$ was also tested from -0.90 to $-0.80 \mathrm{~V}$ (vs. $\mathrm{Hg} / \mathrm{HgO}$ ) with a scan rate from 10 to $100 \mathrm{mV} \mathrm{s}^{-1}$ in $1 \mathrm{M} \mathrm{KOH} \mathrm{(Fig.} 6 \mathrm{c}$ and d). $C_{\mathrm{dl}}$ was calculated with $\Delta J$ at $-0.85 \mathrm{~V}(v s . \mathrm{Hg} / \mathrm{HgO})$. The value of $C_{\mathrm{dl}}\left(\mu \mathrm{F} \mathrm{cm}{ }^{-2}\right)$ was
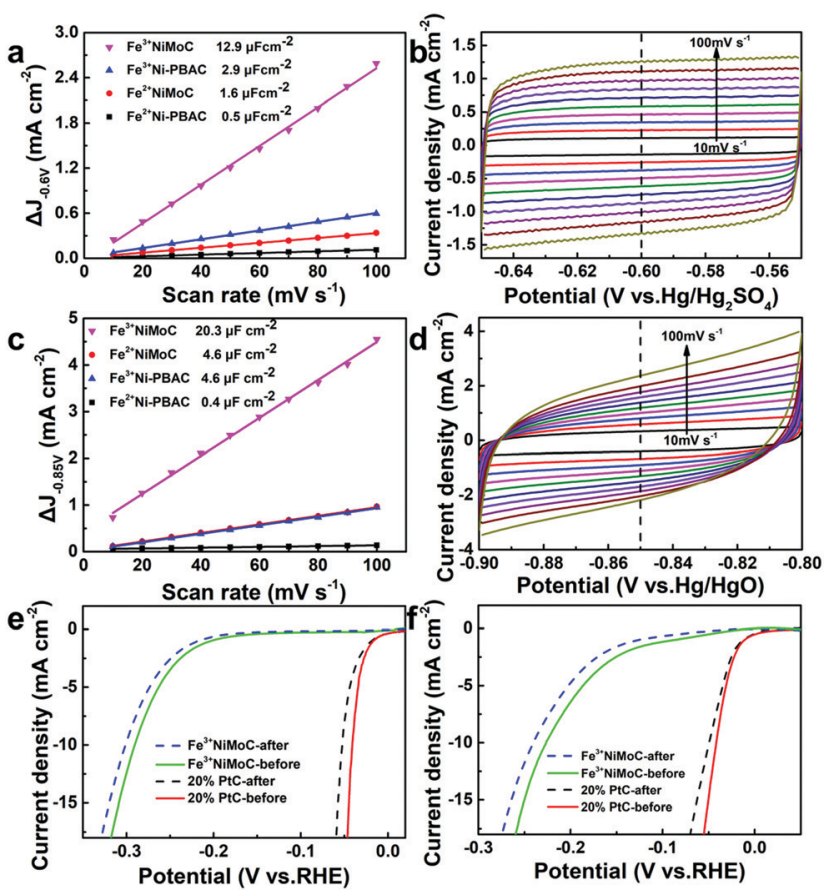

Fig. $6 \mathrm{C}_{\mathrm{dl}} \mathrm{s}$ was calculated with $\Delta \mathrm{J}$ at $-0.60 \mathrm{~V}$ (vs. $\mathrm{Hg} / \mathrm{Hg}_{2} \mathrm{SO}_{4}$ ) in $0.5 \mathrm{M}$ $\mathrm{H}_{2} \mathrm{SO}_{4}$ (a) and the corresponding $\mathrm{CV}$ curves of $\mathrm{Fe}^{3+} \mathrm{NiMoC}$ (b). $\mathrm{C}_{\mathrm{dl}} \mathrm{S}$ was calculated with $\Delta J$ at $-0.85 \mathrm{~V}$ (vs. $\mathrm{Hg} / \mathrm{HgO}$ ) in $1 \mathrm{M} \mathrm{KOH}$ (c) and the corresponding CV curves of $\mathrm{Fe}^{3+} \mathrm{NiMoC}$ (d). iR-corrected LSV curves of $\mathrm{Fe}^{3+} \mathrm{NiMoC}$ and $\mathrm{Pt} / \mathrm{C}$ before and after $10000 \mathrm{CVs}$ in $0.5 \mathrm{M} \mathrm{H}_{2} \mathrm{SO}_{4}(\mathrm{e})$ and in $1 \mathrm{M} \mathrm{KOH}(\mathrm{f})$. 
$20.3 \mu \mathrm{F} \mathrm{cm}{ }^{-2}$ for $\mathrm{Fe}^{3+} \mathrm{NiMoC}, 4.6 \mu \mathrm{F} \mathrm{cm}{ }^{-2}$ for $\mathrm{Fe}^{3+} \mathrm{Ni}-\mathrm{PBAC}$, $4.6 \mu \mathrm{F} \mathrm{cm}^{-2}$ for $\mathrm{Fe}^{2+} \mathrm{NiMoC}$ and $0.4 \mu \mathrm{F} \mathrm{cm} \mathrm{cm}^{-2}$ for $\mathrm{Fe}^{2+} \mathrm{Ni}-\mathrm{PBAC}$. It was assumed that the catalytic effect can be improved with the increasing quantity of catalytically active sites, which is consistent with the results of 3.2 and 3.3.

In order to investigate the durability of the catalyst, CVs were carried out in $0.5 \mathrm{M} \mathrm{H}_{2} \mathrm{SO}_{4}$ or $1 \mathrm{M} \mathrm{KOH}$ solution. $\mathrm{Fe}^{3+}$ NiMoC and $20 \%$ commercial $\mathrm{Pt} / \mathrm{C}$ were electrolyzed from -0.4 to $0 \mathrm{~V}$ (vs. RHE) in $\mathrm{N}_{2}$-saturated $0.5 \mathrm{M} \mathrm{H}_{2} \mathrm{SO}_{4}$ or $1 \mathrm{M} \mathrm{KOH}$ solution with the scan rate of $100 \mathrm{mV} \mathrm{s}^{-1}$ for 10000 segments. In Fig. 6e and $\mathrm{f}$, the LSV curves before and after CVs demonstrate that $\mathrm{Fe}^{3+}$ NiMoC has less current density loss after CVs than commercial $20 \% \mathrm{Pt} / \mathrm{C}$ in $0.5 \mathrm{M} \mathrm{H}_{2} \mathrm{SO}_{4}$ or $1 \mathrm{M} \mathrm{KOH}$, which suggests that $\mathrm{Fe}^{3+} \mathrm{NiMoC}$ is more durable compared to commercial $\mathrm{Pt} / \mathrm{C}$.

\section{Conclusion}

In summary, we synthesized a new carbon cage-encapsulated FeNiMo compound material to electrocatalyze the HER. This non-noble metal catalyst exhibits excellent electrocatalytic performance in both acidic $\left(246 \mathrm{mV}, 10 \mathrm{~mA} \mathrm{~cm}{ }^{-2}\right)$ and alkaline (199 mV, $10 \mathrm{~mA} \mathrm{~cm}^{-2}$ ) solutions. More importantly, we have found a cheap and feasible way to establish a carbon cage structure, which can further enhance the durability of the nonmetal catalyst. In general, this paper provides a promising way to decrease the cost of the catalyst for the HER by using an efficient and durable non-noble metal catalyst to replace the noble-metal one.

\section{Conflicts of interest}

The authors have no competing interests to declare.

\section{Acknowledgements}

This work was supported by National Key R\&D Program of China (No. 2016YFC1102802).

\section{References}

1 P. Lu, Y. Yang, J. Yao, M. Wang, S. Dipazir, M. Yuan, J. Zhang, X. Wang, Z. Xie and G. Zhang, Appl. Catal., B, 2019, 241, 113-119.

2 W. Lubitz and W. Tumas, Chem. Rev., 2007, 107, 3900-3903. 3 J. Zhang, W. Jia, S. Dang and Y. Cao, J. Colloid Interface Sci., 2020, 560, 161-168.

4 Z. Tao, T. Wang, X. Wang, J. Zheng and X. Li, ACS Appl. Mater. Interfaces, 2016, 8, 35390-35397.

5 J. Huang, C. Du, J. Nie, H. Zhou, X. Zhang and J. Chen, Electrochim. Acta, 2019, 326, 134982.

6 J. Tian, Q. Liu, A. M. Asiri and X. Sun, J. Am. Chem. Soc., 2014, 136, 7587-7590.

7 A. Kumar and S. Bhattacharyya, ACS Appl. Mater. Interfaces, 2017, 9, 41906-41915.
8 W. Zhu, R. Zhang, F. Qu, A. M. Asiri and X. Sun, ChemCatChem, 2017, 9, 1721-1743.

9 J. Wang, W. Cui, Q. Liu, Z. Xing, A. M. Asiri and X. Sun, Adv. Mater., 2016, 28, 215-230.

10 T. Y. Ma, S. Dai, M. Jaroniec and S. Z. Qiao, J. Am. Chem. Soc., 2014, 136, 13925-13931.

11 L. Zhang, I. S. Amiinu, X. Ren, Z. Liu, G. Du, A. M. Asiri, B. Zheng and X. Sun, Inorg. Chem., 2017, 56, 13651-13654.

12 X. Ren, W. Wang, R. Ge, S. Hao, F. Qu, G. Du, A. M. Asiri, Q. Wei, L. Chen and X. Sun, Chem. Commun., 2017, 53, 9000-9003.

13 W. Wang, L. Yang, F. Qu, Z. Liu, G. Du, A. M. Asiri, Y. Yao, L. Chen and X. Sun, J. Mater. Chem. A, 2017, 5, 16585-16589.

14 W. Wang, X. Ren, S. Hao, Z. Liu, F. Xie, Y. Yao, A. M. Asiri, L. Chen and X. Sun, Chem. - Eur. J., 2017, 23, 12718-12723.

15 D.-H. Ha, B. Han, M. Risch, L. Giordano, K. P. C. Yao, P. Karayaylali and Y. Shao-Horn, Nano Energy, 2016, 29, 37-45.

16 Y. Zhang, Y. Liu, M. Ma, X. Ren, Z. Liu, G. Du, A. M. Asiri and X. Sun, Chem. Commun., 2017, 53, 11048-11051.

17 T. Liu, D. Liu, F. Qu, D. Wang, L. Zhang, R. Ge, S. Hao, Y. Ma, G. Du, A. M. Asiri, L. Chen and X. Sun, Adv. Energy Mater., 2017, 7, 1700020.

18 T. Liu, L. Xie, J. Yang, R. Kong, G. Du, A. M. Asiri, X. Sun and L. Chen, ChemElectroChem, 2017, 4, 1840-1845.

19 L. Zhang, X. Ren, X. Guo, Z. Liu, A. M. Asiri, B. Li, L. Chen and X. Sun, Inorg. Chem., 2018, 57, 548-552.

20 R. Zhang, X. Ren, S. Hao, R. Ge, Z. Liu, A. M. Asiri, L. Chen, Q. Zhang and X. Sun, J. Mater. Chem. A, 2018, 6, 1985-1990.

21 X. F. Lu, L. Yu, J. Zhang and X. W. Lou, Adv. Mater., 2019, 31, 1900699.

22 N. Cheng, L. Ren, G. Casillas, S. Zhou, J. Zhuang, L. Wang, X. Xu, S. X. Dou and Y. Du, Sustainable Energy Fuels, 2019, 3, 1757-1763.

23 J. Landon, E. Demeter, N. İnoğlu, C. Keturakis, I. E. Wachs, R. Vasić, A. I. Frenkel and J. R. Kitchin, ACS Catal., 2012, 2, 1793-1801.

24 Y. Xu, W. Tu, B. Zhang, S. Yin, Y. Huang, M. Kraft and R. Xu, Adv. Mater., 2017, 29, 1605957.

25 X. F. Lu, L. Yu and X. W. Lou, Sci. Adv., 2019, 5, eaav6009.

26 M. F. Kibria and M. S. Mridha, Int. J. Hydrogen Energy, 1996, 21, 179-182.

27 M. Gong, Y. Li, H. Wang, Y. Liang, J. Z. Wu, J. Zhou, J. Wang, T. Regier, F. Wei and H. Dai, J. Am. Chem. Soc., 2013, 135, 8452-8455.

28 J. Du, C. Chen, F. Cheng and J. Chen, Inorg. Chem., 2015, 54, 5467-5474.

29 A. Subramania, A. R. Sathiya Priya and V. S. Muralidharan, Int. J. Hydrogen Energy, 2007, 32, 2843-2847.

30 X.-Y. Yu, Y. Feng, Y. Jeon, B. Guan, X. W. Lou and U. Paik, Adv. Mater., 2016, 28, 9006-9011.

31 X. Zhao, P. Pachfule, S. Li, J. R. J. Simke, J. Schmidt and A. Thomas, Angew. Chem., Int. Ed., 2018, 57, 8921-8926.

32 F.-X. Ma, H. B. Wu, B. Y. Xia, C.-Y. Xu and X. W. Lou, Angew. Chem., Int. Ed., 2015, 54, 15395-15399. 
33 H. Zhang, S. Hwang, M. Wang, Z. Feng, S. Karakalos, L. Luo, Z. Qiao, X. Xie, C. Wang, D. Su, Y. Shao and G. Wu, J. Am. Chem. Soc., 2017, 139, 14143-14149.

34 J. Wang, D. Gao, G. Wang, S. Miao, H. Wu, J. Li and X. Bao, J. Mater. Chem. A, 2014, 2, 20067-20074.

35 X. Fan, Z. Peng, R. Ye, H. Zhou and X. Guo, ACS Nano, 2015, 9, 7407-7418.

36 Q. Qin, H. Jang, L. Chen, G. Nam, X. Liu and J. Cho, Adv. Energy Mater., 2018, 8, 1801478.

37 Y. Cao, H. Wang, R. Ding, L. Wang, Z. Liu and B. Lv, Appl. Catal., A, 2020, 589, 117308.

38 L. Liu, N. Chen, Y. Lei, X. Xue, L. Li, J. Wang, S. Komarneni, H. Zhu and D. Yang, J. Hazard. Mater., 2018, 360, 279-287.

39 S. Bai, C. Chen, D. Zhang, R. Luo, D. Li, A. Chen and C.-C. Liu, Sens. Actuators, B, 2014, 204, 754-762.

40 Q. Zhao, Z. Yan, C. Chen and J. Chen, Chem. Rev., 2017, 117, 10121-10211.

41 L. Cong, Z. Yu, F. Liu and W. Huang, Catal. Sci. Technol., 2019, 9, 1208-1214.

42 R. S. Mann and K. C. Khulbe, Bull. Chem. Soc. Jpn., 1975, 48, 1021-1023.
43 Z. Li, J. Ma, B. Zhang, C. Song and D. Wang, CrystEngComm, 2017, 19, 1479-1485.

44 X.-F. Lu, L.-F. Gu, J.-W. Wang, J.-X. Wu, P.-Q. Liao and G.-R. Li, Adv. Mater., 2017, 29, 1604437.

45 H. Perron, T. Mellier, C. Domain, J. Roques, E. Simoni, R. Drot and H. Catalette, J. Phys.: Condens. Matter, 2007, 19, 346219.

46 E. J. Sundstrom, X. Yang, V. S. Thoi, H. I. Karunadasa, C. J. Chang, J. R. Long and M. Head-Gordon, J. Am. Chem. Soc., 2012, 134, 5233-5242.

47 J. Wang, F. Xu, H. Jin, Y. Chen and Y. Wang, Adv. Mater., 2017, 29, 1605838.

48 H. Gao, J. Zang, X. Liu, Y. Wang, P. Tian, S. Zhou, S. Song, P. Chen and W. Li, Appl. Surf. Sci., 2019, 494, 101-110.

49 Q. Zhang, H. Zhong, F. Meng, D. Bao, X. Zhang and X. Wei, Nano Res., 2018, 11, 1294-1300.

50 Y. Yang, Z. Lun, G. Xia, F. Zheng, M. He and Q. Chen, Energy Environ. Sci., 2015, 8, 3563-3571.

51 M. A. Lukowski, A. S. Daniel, F. Meng, A. Forticaux, L. Li and S. Jin, J. Am. Chem. Soc., 2013, 135, 10274-10277. 